\title{
Forum
}

\section{The Plague of Athens Shedding Light on Modern Struggles with COVID-19}

\author{
Jilene Malbeuf, Peter Johnson, John Johnson and Austin Mardon \\ University of Alberta and Antarctic Institute of Canada
}

Key words: COVID-19, Plague of Athens, disease, moral decay, lockdown fatigue, pyschological impact, Peloponnesian War, Thucydides

In 2020, we are facing unprecedented times, and as some form of lockdown continues with no signs of ending feelings of hopelessness are completely natural and understandable. Unprecedented times does not mean that these current issues and struggles have never been faced by humanity before, however. The Spanish Flu which took place after World War One and the Black Death that was rampant in Asia and Europe in the 14th century quickly come to mind as examples of past pandemics, but these are only two examples of devastating diseases throughout human history. The Plague of Athens that was raging during the beginning of the Peloponnesian War in $430 \mathrm{BCE}$ is another such example. Though removed from our current situation by many centuries, its symptoms and the effects it had on the population of Athens have been meticulously recorded by the general and historian Thucydides, giving us the opportunity to compare his account to our own experiences today. The disease may be different, and the image he portrays may be more violent and desperate than our own, but nonetheless we can see similarities in how these two separate societies have reacted to unforeseen hardships. In this comparison, we can come to understand at once our own good fortune at going through a pandemic with the support of modern technology and medicine as well as how universal our reactions are to this type of suffering, thereby making it natural rather than shameful. Humanity has faced a great deal of diversity before, and COVID-19 will likely prove to be no different.

The Peloponnesian War provides necessary historical context for understanding the Plague of Athens and the people's response to it. In its entirety, the war lasted from 431-404 BCE, with three distinct phases. The plague occurred in the second year of the war, so for the purpose of historical context only the first phase (431-421 $\mathrm{BCE}$ ) is relevant. This was known as the Archidamian War, named after the king of Sparta at the time. Sparta, as head of the Peloponnesian League, went against Athens, as head of the Delian League, for various infractions against the negotiated peace between these two empires. Pericles was the general initially responsible for

Author of correspondence: Jilene Malbeuf, E-mail: jilene@ualberta.ca

Cite this article: Malbeuf J, Johnson P, Johnson J and Mardon A (2021). The Plague of Athens Shedding Light on Modern Struggles with COVID-19. The Journal of Classics Teaching 22, 47-49. https://doi.org/10.1017/S2058631021000064 commanding the Athenian forces and responding to the threat. One particularly important response was to have all nearby inhabitants of Attica evacuated from their homes and relocated within the safety of the walls surrounding Athens and its connected port town Piraeus. While this may appear to be sound advice for protecting the people of Attica from invaders, the resulting massive overpopulation of the city was a major cause of the plague that ravaged those people soon after. Thucydides is another important Athenian general, as his History of the Peloponnesian War is the detailed primary source material that provides historians with a wealth of information about the war as well as the plague. It is his words that offer a sense of how devastating this disease was, not only because of the death toll but also because of its psychological impact on the population as a whole.

Thucydides' account of these events begins roughly six months earlier in the winter of $431 / 430$ BCE, with an account of Pericles' funeral oration after the first couple of battles took place. This was part of a traditional rite that celebrated the sacrifice of those soldiers lost in battle. Donald Nielsen (1996) recounts how:

Pericles's speech undoubtedly gives an idealized portrait of Athenian culture and virtue... A particularly central issue is the prominence given to the notions of balance and harmony of opposites. [...] While he specifies a number of defining features of Athenian civil religion, they are generally enumerated in pairs and bound together by the balance which exists between the members of each pair. (Nielsen, 1996, p. 399)

An example of this type of binary would be praise for how Athenians can pride themselves on having a rational mind without being too soft because of it. Harmony, balance and moderation were key elements that were celebrated in Athenians, and what gave them a sense of political superiority in comparison to other citystates like Sparta, at least in their minds. These qualities were found in the individual rather than enforced by the government, a sentiment which made it seem only natural that they should be recognised as the superpower in the Aegean - an attitude that contributed to the outbreak of war in the first place. As an ancient historian, Thucydides was free to take dramatic licence on the event 
that he was recording, but this type of speech would have been typical for a funeral oration. The dramatic licence becomes clear in how he places it immediately before his account of the plague which began roughly six months later, which exhibits the moral decay of these idealised citizens.

Thucydides' account of the plague is remarkable for its detail and apparent objectivity, so much so that some recent scholars have come to consider the plague as more important than the war in which it arose (Morgan, 1994, p. 197). Despite his apparent devotion to recording this disease, he is reluctant to decide on a specific cause for it, stating in book two of The Peloponnesian War:

Let anyone, whether doctor or layman, say as each perceives the likely origin of the plague and whatever causes he believes of sufficient power to have produced so great a change; I will restrict myself to a description of the symptoms, on the basis of which anyone examining them would from foreknowledge recognize the disease should it ever attack again. (Thucydides, in Kallet, 2013, p. 358)

Ironically, one of the reasons that this passage has garnered so much attention is that it is impossible to determine what disease caused this plague despite the wealth of information Thucydides provides (Morgan, 1994, pp. 200-3). Thucydides approaches the plague with a critical eye, aiming to objectively record whatever empirical evidence he has witnessed, following the teachings of Hippocrates and the medical literature of his time. However, inaccuracies are still prevalent, and the disease is impossible to label by a modern audience based on the information provided. This is likely due to some combination of inconsistencies between ancient and modern understandings of disease, lack of medical training on Thucydides' part, and any dramatic licence he may have taken in writing this narrative. Sparing the gruesome details, this plague attacked the respiratory and digestive systems in turn and had a high mortality rate - one expedition recorded that it took almost $40 \%$ of its forces within a span of 40 days (Kallet, 2013, pp. 367368). The outbreak began in Piraeus in the days after a Spartan invasion, which led people to suspect that the Spartans had managed to contaminate the wells of the port (Kallet, 2013, pp. 356-357). The enemy continued with its planned invasion seemingly without fear of contamination, and in fact did not seem to be affected by it, making this suspicion reasonable and justified.

Another potential cause of the disease that would be more natural to consider by contemporary and modern readers alike would be the overcrowding of Athens. All Greeks took their religion very seriously, so Apollo as the god of healing and diseases would automatically be involved somehow. With the evacuation of the countryside, household gods and shrines would have been abandoned, and this influx of people into Athens would necessitate that spaces previously deemed sacred and thus uninhabitable would now need to be populated (Kallet, 2013, p. 371). From a religious perspective these two trends would understandably attract the wrath of the gods, and from the modern perspective this shows how limited for space Athenians must have been in order to risk such divine retribution. Such confines within the walls of the city would be the perfect breeding ground for diseases, especially without a modern awareness of the importance of good hygiene.

Beyond recording the effects of this disease so that it may be recognised in the future, Thucydides uses this devastating chapter in Athenian history to highlight the destructive impact of war on Athenians, who were at the height of their power prior to this conflict and thus had a dramatic fall because of it. Morgan (1994) aptly summarises the picture that Thucydides portrays of Athens at war:

The description of the disease, which is clearly a result of conditions such as overcrowding brought about by the war, is a literary device emphasizing the triple destruction of crops, people, and animals by the war and its accompanying pestilence....He describes the disease in horrifying detail and then shows that it leaves its victims so weakened in mind as well as in body that individual and collective mores collapse, men look only for pleasure and refuse to fight, the gods are forgotten, temples are desecrated, funeral pyres stolen, and the dead go unburied in Athens while the countryside is wasted. (Morgan, 1994, p. 205)

The Plague combined with the destruction of crops and livestock by the Spartans would have made for a particularly hopeless atmosphere within the city. Nielsen (1996) expands on this point by explaining that 'abrupt changes of fortune took place in which the rich died and the penniless inherited their wealth. Since everything including money seems ephemeral self-indulgence and pleasure became the order of the day. Honor was cast aside, no one would abide by the laws and only the pleasure of the moment was valued' (Nielsen, 1996, p. 400). This type of behaviour provides a dramatic contrast to the idealised Athenians that Pericles described in his funeral oration, emphasising the depth of moral decay in the citizens when faced with such unimaginable suffering and loss (Nielsen, 1996, p. 402; Morgan, 1994, p. 207).

Today, with the threat of COVID-19, we are not facing such a fatal plague or an invading force destroying our livelihood so our reaction to this prevalent disease has not been as extreme as can be seen in the Athenians. Nonetheless, similarities can be felt in the constant state of panic leading to a sense of moral decay within society. Feeling of shock and fear at the threat of a disease that is without a cure or vaccine cannot be maintained indefinitely, and after months of this new reality that fear has begun to give way to exhausted indifference. Daily life must somehow continue, even when life as we know it has been disrupted. This growing apathy has been labelled as 'lockdown fatigue', whereby people's commitment to safety measures wanes and all emotions seem to be replaced by exhaustion as time goes on. William Park (2020) reports on how this extended period of isolation with its disruption of daily habits can be emotionally taxing:

'Making decisions is effortful, which is why we make habits. We don't want to have to make decisions all the time', says Sarah Tracy, who studies emotion and human communication at Arizona State University. 'In this situation [of a global pandemic and mass protests] many things that were habitual are no longer habits, like commuting, how we dress ourselves in public, visiting family, and our way of shopping, so we have to make decisions about them'. (quoted in Park, 2020, para.4)

Decisions constantly made in isolation without any feedback can be demoralising, and without human connection it can also become more difficult to be compassionate, which can in turn further feed into feelings of isolation. While we may still have hope for tomorrow (unlike those Athenians who came to forsake their pride in morality for immediate pleasures), the new reality of society under the threat of COVID-19 has altered our values. 
In conclusion, similarities can persist in vastly different times and cultures when they are faced with the similar threat of a disease without a cure. Advancements in medicine and technology may lessen the ill effects of COVID-19 in comparison to the Plague of Athens, but it is not enough to eradicate the mental traumas that are connected to living for an extended time in fear of the outside world and an invisible enemy. During the Peloponnesian War, Athens descended from a temperate and civilised society to one full of death and lawlessness in response to the dual attack of plague and war. Values were abandoned then just as they are now, albeit to a greater extreme in response to their greater threat. Centuries later, we can sympathise with their plight by seeing a hint of it in our own, showing that what we are feeling now is a natural and universal human reaction to a devastating but temporary danger, and as such we should not feel shame for our feelings of hopelessness in these trying times.

\section{References}

Kallet L (2013) Apollo, the Plague, and the War. The American Journal of Philology 134, 3, pp. 355-382.

Morgan TE (1994) Plague or Poetry? Thucydides on the Epidemic at Athens. Transactions of the American Philological Association (1974-2014) 124, pp. 197-209.

Nielsen DA (1996) Pericles and the Plague: Civil Religion, Anomie, and Injustice in Thucydides. Sociology of Religion 57, 4, pp. 397-407.

Park W (2020). The Real Reason Lockdown is Exhausting. BBC online. Available at: https://www.bbc.com/future/article/20200623-the-real-reasonlockdown-is-exhausting (accessed 16 January 2021). 